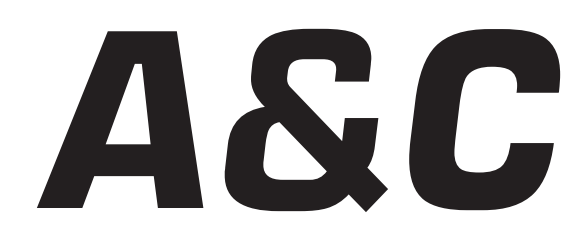

Revista de Direito Administrativo \& Constitucional

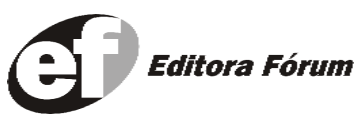

A\&C R. de Dir. Administrativo e Constitucional, Belo Horizonte, ano 5, n. 21, p. 1-252, jul./set. 2005 


\section{A\&C REVISTA DE DIREITO ADMINISTRATIVO E CONSTITUCIONAL}

\section{IPDA}

Instituto Paranaense

de Direito Administrativo

Direção Geral

Romeu Felipe Bacellar Filho

Direção Editorial

Paulo Roberto Ferreira Motta

Direção Executiva

Emerson Gabardo

Conselho de Redação

Edgar Chiuratto Guimarães

Adriana da Costa Ricardo Schier

Célio Heitor Guimarães

Conselho Editorial

Adilson Abreu Dallari

Alice Gonzáles Borges

Carlos Ari Sundfeld

Carlos Ayres Britto

Carlos Delpiazzo

Cármen Lúcia Antunes Rocha

Celso Antônio Bandeira de Mello

Clèmerson Merlin Clève

Clóvis Beznos

Enrique Silva Cimma

Eros Roberto Grau

Fabrício Motta

Guilhermo Andrés Muñoz (in memoriam)

Jaime Rodríguez-Arana Muñoz

Jorge Luís Salomoni
José Carlos Abraão
José Eduardo Martins Cardoso

José Luís Said

José Mario Serrate Paz

Juan Pablo Cajarville Peruffo

Juarez Freitas

Julio Rodolfo Comadira

Luís Enrique Chase Plate

Lúcia Valle Figueiredo

Manoel de Oliveira Franco Sobrinho

(in memoriam)

Marçal Justen Filho

Marcelo Figueiredo

Márcio Cammarosano

Maria Cristina Cesar de Oliveira
Nelson Figueiredo

Odilon Borges Junior

Pascual Caiella

Paulo Eduardo Garrido Modesto

Paulo Henrique Blasi

Paulo Neves de Carvalho (in memoriam)

Paulo Ricardo Schier

Pedro Paulo de Almeida Dutra

Regina Maria Macedo Nery Ferrari

Rogério Gesta Leal

Rolando Pantoja Bauzá

Sérgio Ferraz

Valmir Pontes Filho

Yara Stropa

Weida Zancaner

\footnotetext{
A246 A\&C Revista de Direito Administrativo e Constitucional. ano 3, n. 11, jan./mar. 2003. Belo Horizonte: Fórum, 2003.

Trimestral

ano 1, n.1, 1999 até ano 2, n.10, 2002 publicada pela Editora Juruá em Curitiba

ISSN: 1516-3210

1. Direito Administrativo. 2. Direito Constitucional. I. Fórum.
}

CDD: 342 CDU: 33.342

(c) Editora Fórum Ltda. 2005

Todos os direitos reservados. É proibida a reprodução total ou parcial, de qualquer forma ou por qualquer meio eletrônico ou mecânico, inclusive através de processos xerográficos, de fotocópias ou de gravação, sem permissão por escrito do possuidor dos direitos de cópias (Lei $n^{\circ}$ 9.610, de 19.02.1998).

Editora Fórum Ltda

Av. Afonso Pena, 2770 - 15\%16ªndar - Funcionários

CEP 30130-007 - Belo Horizonte/MG - Brasil

Tel.: 08007043737

Internet: www.editoraforum.com.br

e-mail: editoraforum@editoraforum.com.br
Editor responsável: Luís Cláudio Rodrigues Ferreira Projeto gráfico e diagramação: Luis Alberto Pimenta Revisora: Olga M. A. Sousa

Pesquisa jurídica: Fátima Ribeiro - OAB/MG 74868

Bibliotecária: Nilcéia Lage de Medeiros

CRB 1545/MG 6a região

Os conceitos e opiniões expressas nos trabalhos assinados são de responsabilidade exclusiva de seus autores.

Impressa no Brasil / Printed in Brazil

Distribuída em todo Território Nacional 


\title{
Gratuidade sem Custeio ou Revisão Tarifária no Serviço Público de Transporte Rodoviário de Passageiros: o Vitupério à Constituição
}

\author{
Sérgio Roberto Maluf \\ Advogado. Pós-graduando do Instituto de Direito Romeu Felipe Bacellar
}

Sumário: 1 Introdução - 2 Serviço público de transporte rodoviário de passageiros - 3 Fundamentos legais - 4 O cotejo da norma infraconstitucional com a Constituição - 5 A separação dos poderes - 6 Conclusão - Bibliografia

\section{Introdução}

O transporte gracioso é, hodiernamente, motivo de propostas legislativas nas esferas dos municípios, dos estados e, também, no âmbito federal. Parlamentares apresentam-se travestidos de justiceiros, no melhor estilo lendário, impondo, em ato único de suas penas, ônus aos particulares concessionários do serviço público de transporte rodoviário de passageiros em favor do transporte exonerado de custos, do qual irá beneficiar-se qualquer grupo da sociedade que, justificativa maior, necessitam daquele serviço público e com ele não podem arcar.

O concessionário, ou mesmo o permissionário, vê, sem qualquer defesa possível, a subtração de parcelas de sua receita, angariada sob a forma de tarifa, forma única de fazer frente às despesas que o serviço prestado constitui. Obriga-se a assumir, ainda que em flagrante ilegalidade, ônus que lhe é imposto por uma sociedade, em teoria, representada pelos parlamentares e seus miraculosos projetos.

Não se lhe apresenta, em qualquer daquelas instâncias, controles constitucionais preventivos, autorizados e constituídos pelas Comissões de Constituição e Justiça de todas as casas legislativas e também pelos chefes do Poder Executivo, fazendo-o através do poder de veto. ${ }^{1}$ Algumas vezes faz-se presente, sim, o Poder Judiciário, exercendo controle repressivo de constitucionalidade por via de ação (método concentrado) ou por via de defesa (método difuso) ${ }^{2}$ e ceifando qualquer tentativa de ilegalidade,

NOGUEIRA DA SILVA, Paulo Napoleão. Curso de Direito Constitucional, p. 269. Para o autor, no Brasil o controle de constitucionalidade faz-se em dois momentos: preventivo e repressivo. Aquele realizado pelo Poder Legislativo e Poder Executivo (antes da vigência da lei); este realizado pelo Poder Judiciário (através do controle difuso e do controle concentrado de constitucionalidade).

2 BASTOS, Celso Ribeiro. Curso de Direito Constitucional, p. 407. 
ainda que impregnada de comoção social ou aspectos de injustiça, fruto da abordagem populista onde as gratuidades do legislador infraconstitucional se amparam.

Destarte, impende rápida abordagem do que seja o serviço público do transporte rodoviário de passageiros, noções jurídicas da atividade e fundamentos legais que o suportam. Daí advém a presença do concessionário ou permissionário, em mantença contratual com o Estado que deva lhe assegurar a necessária contra-partida do serviço que se propõe a prestar, representada pelo justo equilíbrio econômico-financeiro inferido quando encetada a relação com o Poder Público.

Por fim, cumpre estratificar as gratuidades hoje postas, já que fartos os projetos de lei existentes. Urge cotejá-las com a Carta Magna e com a própria legislação infraconstitucional existente, parâmetros únicos capaz de revestir qualquer benesse tarifária de legalidade e legitimidade, afiançada assim em seus aspectos formal e material.

\section{Serviço público de transporte rodoviário de passageiros}

A sociedade, enquanto reunião de indivíduos organizados em grupo coeso, tem noção de atividades que o grupo ali reunido pode desenvolver individualmente e de atividades que só é possível sua execução mediante o esforço de todos. Tal conscientização passa, indubitavelmente, por fatores externos aos indivíduos, tais como influências econômicas, tecnológicas, temporais e espaciais.

É então que elege, o grupo social, e a seu tempo, necessidades tidas como de interesse de todos e só possível sua execução pela entidade organizada para gerir os interesses daquele grupo: transfere-se, ao Estado, a organização e execução do que passou a denominar-se serviço público. Outros grupos, em outras épocas, podem eleger atividades outras que sejam próprias de seus interesses para elencarem o rol dos serviços públicos.

São, assim, no dizer de Horácio Augusto Mendes de Souza, prestações "transferidas da sociedade para o Estado, tendo em vista o reconhecimento dos indivíduos acerca da impossibilidade de exercerem, por si sós, tais atividades em obséquio ao princípio da subsidiariedade." ${ }^{3}$ Há, nestes casos, assentamento no texto constitucional das atividades transferidas, o que, por si, delimita o campo prestacional do Estado.

${ }^{3}$ MENDES DE SOUZA, Horácio Augusto. Regulação Jurídica do Transporte Rodoviário de Passageiros, p. 26.

A \& C R. de Dir. Administrativo e Constitucional, Belo Horizonte, ano 5, n. 21, p. 89-98, jul./set. 2005 
Em sua essência, a doutrina apresenta caracteres distintos para serviços públicos. É da lavra de Hely Lopes Meirelles que colhemos definição genérica que abrange aspectos formais e materiais de serviço público:

Serviço público é todo aquele prestado pela Administração ou por seus delegados, sob normas e controles estatais, para satisfazer necessidades essenciais ou secundárias da coletividade ou simples conveniências do Estado. ${ }^{4}$

Diogenes Gasparini, em sua obra, faz análise do serviço público sob ótica orgânica (onde resplandece o aspecto subjetivo da atividade com órgãos, agentes e recursos da Administração destinados à satisfação das necessidades dos administrados), sob ótica material (com o objetivo da atividade) e, por fim, sob ótica formal (é atividade desenvolvida sob regras exorbitantes do Direito Comum). ${ }^{5}$ Destarte, extrai-se, do aspecto formal, a submissão ao regime do Direito Público quando da execução da atividade, quer seja diretamente pelo Estado, quer seja por particular delegatário.

É o caso do transporte coletivo rodoviário de passageiros. Há delegatários em quase todos os seus modais (urbano, intermunicipal e interestadual), sujeitos, então, ao Regime de Direito Público.

Remunera-se, o serviço público, através de taxa ou tarifa. Assevera Diogenes Gasparini que, tendo o serviço remuneração, independente do seu uso pelo administrado, estar-se-ia diante de típica cobrança de taxa (ensejada pela simples oferta da facilidade). Já aos serviços públicos facultativos, como o transporte coletivo, remunera-se através de tarifa ou preço público. Em ambos os casos, deve a remuneração compensar adequadamente a prestação dos serviços, reduzindo-se em fórmula que abarque o custo do capital, o melhoramento e expansão dos serviços, além do necessário lucro que busca o particular na exploração da atividade. ${ }^{6}$ Perfaz-se, assim, o equilíbrio econômico-financeiro que deve ser mantido durante todo o prazo de execução dos serviços, de forma paritária ao que definido no momento vestibular da delegação.

\section{Fundamentos legais}

No Brasil, foi a Constituição Federal de 1988 que elegeu a atividade de transporte rodoviário interestadual e internacional de passageiros

\footnotetext{
${ }^{4}$ MEIRELLES, Hely Lopes. Direito Administrativo Brasileiro, p. 319.

${ }^{5}$ GASPARINI, Diogenes. Direito Administrativo, p. 266.

${ }^{6}$ Id., Ibid., p. 276.
}

A \& C R. de Dir. Administrativo e Constitucional, Belo Horizonte, ano 5, n. 21, p. 89-98, jul./set. 2005 
como serviço público, a ser prestado diretamente ou mediante concessão, permissão ou autorização. ${ }^{7}$

Ademais, extrai-se da Magna Carta, consoante o ensinamento de José Afonso da Silva, interpretando-se o Artigo 175, norma constitucional de eficácia limitada ou reduzida, já que patente seu enquadramento no grupo de normas que "somente incidem totalmente sobre esses interesses após uma normatividade ulterior que lhe desenvolva a eficácia”. ${ }^{8}$

Impõe-se a incumbência da prestação do serviço público ao poder público (Estado), na forma prevista pela lei, diretamente ou sob o regime de concessão ou permissão (suprimindo-se aqui a autorização). ${ }^{9}$ Dispõe ainda a Constituição, cimentando o enquadramento de norma constitucional de eficácia limitada, que a lei disporá sobre o regime dos concessionários ou permissionários, os direitos dos usuários, a política tarifária e a obrigação de manter-se o serviço adequado.

Eximi-se, assim, o texto constitucional de adentrar na seara tarifária ou na composição de seus custos, notadamente nos parâmetros que irão compor o precitado equilíbrio econômico-financeiro. A esquiva, porém, não é completa. O Artigo 230, no rol das disposições relativas à família, à criança, ao adolescente e ao idoso, impôs, através do constituinte originário, benesse aos maiores de 65 anos nos transportes coletivos urbanos.

Foi o que definiu o poder constituinte originário em sua tarefa de instituir um novo Estado. Fê-lo, por certo, demonstrando o pensamento social da época que acabou por traduzir-se no texto constitucional, valendose do poder isento de limites que lhe foi conferido, à época. ${ }^{10}$ Contratos já firmados e contratos a serem firmados ulteriormente à Constituição, teriam que suportar tal gratuidade, sem que isto representasse, diretamente, obrigatoriedade de contra-partida por parte do Poder Concedente. O que se traduz em meia-verdade.

Forçoso abordar, desde já, o conceito técnico do cálculo tarifário a fim de, sem delongas, encastelar o que supra afirmado. A contra-partida

\footnotetext{
7 BRASIL. Constituição da República Federativa do Brasil. Artigo 21, XII, "e".

8 AFONSO DA SILVA, José. Aplicabilidade das Normas Constitucionais, p. 82-83.

9 Sobre o tema ver JUSTEN FILHO, Marçal. Curso de Direito Administrativo, p. 484-485. Entende o autor, reformulando seu próprio posicionamento, que o rol existente no Artigo 21 do texto constitucional não podem ser assumidos como serviços públicos, e por tal impossíveis de modificações ou inovações por parte do legislador infraconstitucional. Aquelas atividades seriam, ainda segundo o autor, qualificadas como serviços públicos "de acordo com as circunstâncias", notadamente quando as atividades voltaremse ao atendimento direto e imediato de direitos fundamentais. Desvinculada a atividade da satisfação daqueles direitos, sobrestaria, então, uma "atividade econômica em sentido estrito (ou um serviço de interesse público)".

${ }^{10}$ NOGUEIRA DA SILVA, Paulo Napoleão, ibid., p. 59.
} 
do concessionário ou permissionário será, como já dito, decorrente da tarifa cobrada. Esta tarifa será, em apertadíssima síntese, a partilha dos custos apresentados pelo serviço público pelo número de usuários pagantes. Oras, maior o número de pagantes, menor o custo tarifário individual. Menor o número de pagantes, maior o custo individualizado. Daí possível afirmar que o preceito constitucional, legitimado pelo poder constituinte originário, é ônus a ser suportado pelos usuários, fruto do decréscimo do número de pagantes. Obrigou-se o Estado concedente do serviço público a recompor o equilíbrio econômico-financeiro dos contratos, afetados em seu divisor mor: o número de usuários pagantes. Cinge-se, aí, a obrigatoriedade do Poder Concedente à época da inauguração do Estado materializado na Constituição Federal de 1988.

Adiante, e atendendo ao chamado constitucional, engastou o legislador ordinário no ordenamento jurídico pátrio as normas vazadas nas Leis $\mathrm{n}^{0}$ 8.987/95 (Regime de concessão e permissão da prestação de serviços públicos previsto no Artigo 175 da Constituição Federal) e $\mathrm{n}^{\mathrm{o}}$ 9.074/95 (Normas para outorga e prorrogações das concessões e permissões, donde se extrai, para o serviço público de transporte em tela, mandamentos gerais contidos em alguns de seus artigos).

Em ambos os diplomas determinações atinentes à graciosidade dos serviços podem ser visualizadas. No texto legal que define o regime de concessão e permissão dos serviços públicos (Lei no $\left.{ }^{8} .987 / 95\right),{ }^{11}$ dedicou o legislador ordinário capítulo integral para regrar a política tarifária (capítulo IV). Oportuno o destaque do que disposto no Artigo $9^{\circ}$ da Lei, determinando que a tarifa será preservada pelas regras de revisão legais, do edital e contratuais. Também no $\S 4^{\circ}$ do mesmo Artigo, há imposição de restabelecimento concomitante quando da alteração unilateral do contrato.

Já o texto da Lei $\mathrm{n}^{\circ}$ 9.074/95 vai mais adiante. Detalha, de forma inequívoca, em seu Artigo 35, o que atinente à concessão de graciosidade tarifária, verbis:

Art. 35. A estipulação de novos benefícios tarifários pelo poder concedente, fica condicionada à previsão, em lei, da origem dos recursos ou da simultânea revisão da estrutura tarifária do concessionário ou permissionário, de forma a preservar o equilíbrio econômico-financeiro do contrato.

${ }^{11}$ BRASIL. Lei n 8.987/95, capítulo IV, artigos 8ª 13.

A \& C R. de Dir. Administrativo e Constitucional, Belo Horizonte, ano 5, n. 21, p. 89-98, jul./set. 2005 
Parágrafo único. A concessão de qualquer benefício tarifário somente poderá ser atribuída a uma classe ou coletividade de usuários dos serviços, vedado, sob qualquer pretexto, o benefício singular.

\section{0 cotejo da norma infraconstitucional com a Constituição}

Irretocável o legislador da norma infraconstitucional vazada na Lei $\mathrm{n}^{\mathrm{o}}$ 9.074/95. Impondo ao benefício do transporte gracioso o necessário traço da impessoalidade, fez, também, exigência da previsão, em lei, da origem dos recursos ou da simultânea revisão da estrutura tarifária.

Forma em que, havendo afetação do número de usuários pagantes da tarifa cobrada, obriga-se o Poder Concedente em realizar a simultânea revisão tarifária. Desimcumbir-se-á o Poder Concedente quando a norma trazer em seu bojo a origem dos recursos para compensação do impacto causado.

A ausência da indicação de custeio, feita em lei, de per si, ensejaria o entendimento da norma como se preceito constitucional fosse. Somente o texto maior pode, através do constituinte originário ou mesmo do constituinte derivado, inovar na concessão da graciosidade que seja, como já demonstrado, suportada por todos. Vedada é a inovação constitucional pelo legislador ordinário, através de lei ordinária, ao que se fulmina, de plano, com a seta da inconstitucionalidade.

Relevado o processo legislativo em seu todo, não há de se olvidar que o Poder Executivo dele também participa. E o faz, no indefectível ensinamento de Clèmerson Merlin Clève, intervindo em uma das fases da elaboração da lei ou elaborando, ele mesmo, ato normativo. ${ }^{12}$

Tal participação, quando em uma das fases da lei, pode ainda se dar de duas formas: com o encaminhamento de proposta originada no Poder Executivo a provocar a atividade do Poder Legislativo ou exercendo seu poder de sanção ou veto em projetos oriundos do órgão legislador.

A não indicação da fonte de custeio em normas que imponham transporte gracioso, quando na seara do ordenamento infraconstitucional, faz com que seja afrontada, visceralmente, a Constituição Federal, já que propõe alargamento das benesses concedidas na Carta Magna. Maculase, tal procedimento, pela insubsistência do processo legislativo adotado, ao pretender-se inovar na Constituição sem que o processo legislativo de Emenda Constitucional seja obedecido. É ato inválido em ordenamentos que adotam, como aqui, Constituições rígidas.

Mas o vício não poderia, ainda, ficar patente pela escoteira alegação ${ }^{12}$ CLÈVE, Clèmerson Merlin. Atividades Legislativa do Poder Executivo, p. 99.

A \& C R. de Dir. Administrativo e Constitucional, Belo Horizonte, ano 5, n. 21, p. 89-98, jul./set. 2005 
de que não há previsão legal da norma para fonte de custeio. Admite, pelo que já abordado, a norma, via alternativa de recomposição do equilíbrio econômico-financeiro pactuado com o delegatário: a simultânea revisão tarifária. Resta perquirir, por fim, em que momento deverá existir ou ser ordenado tal procedimento, impregnando de legalidade, com isto, a norma até então de caráter "quase-inconstitucional".

\section{A separação dos poderes}

Há, no Estado de Direito, assentado em texto constitucional, sopesada sua idéia de unidade, uma divisão de funções entre órgãos que o compõem, dotados, por sua vez, de autonomia ao que denominamos "poderes". ${ }^{13}$

As funções estatais separam-se em atividades judicantes, legiferantes e executivas, abarcadas dentro de um único poder político, indivisível, de titularidade do povo.

Analisamos, no arrazoado dantes grafado, a atividade do Poder Legislativo, ao pretender lançar no ordenamento jurídico norma infraconstitucional que conceda graciosidade no transporte. Não se lhe afigura, pela tipicidade de suas atividades, qualquer determinação para que "ordene" revisão tarifária. Cabe-lhe, por certo, legislar e o que deliberado esteja fielmente traduzido naqueles que sejam seus atos típicos.

Resta deitar olhos para desagasalhar se seria esta, ou não, uma das funções típicas do Poder Executivo. Se há competência para exaração de tal mandamento simultaneamente, como requer a norma de concessões, à sanção (ou mesmo promulgação) da lei que ditamos por "quase-inconstitucional".

Ainda que partícipe do processo legislativo, tem o Poder Executivo, através do Presidente da República, funções próprias, definidas no texto constitucional e que, reduzido o espectro da análise ao serviço público do transporte coletivo rodoviário de passageiros, consubstancia-se em expedição de decretos e regulamentos para fiel execução das leis.

Há, neste ínterim, que se destacar a prerrogativa dada ao Chefe do Poder Executivo federal para iniciar, de forma privativa, todo e qualquer processo legislativo que disponha sobre serviço público, ${ }^{14}$ o que já espanca leis de iniciação nas casas legislativas. ${ }^{15}$ Adotando como paradigma o

\footnotetext{
${ }^{13}$ CLÈVE, Clèmerson Merlin. Ibid., p. 30.

${ }^{14}$ BRASIL. Constituição da República Federativa do Brasil, artigo 61, II, "b".

A \& C R. de Dir. Administrativo e Constitucional, Belo Horizonte, ano 5, n. 21, p. 89-98, jul./set. 2005
} 
Chefe do Poder Executivo federal, a lei de sua iniciativa já deveria conter a indicação de fonte de custeio para qualquer gratuidade no transporte. Não havendo, estar-se-ia diante daquilo que denominamos norma "quaseinconstitucional", devendo fazê-lo, ainda o mesmo Chefe do Executivo, quando da sanção ou quando da inserção da norma no ordenamento através de promulgação pela casa legislativa. ${ }^{16}$

Presente a norma que conceda a gratuidade, sem a indicação do custeio, necessária a intervenção do Poder Executivo, exarando ato que culmine na necessária revisão tarifária, conferindo, àquela norma, contornos de legalidade.

\section{Conclusão}

Ao particular, concessionário ou permissionário da execução de serviço público de transporte rodoviário de passageiros, incumbe, na esmagadora maioria das proposições legislativas, suportar o ônus da benesse ofertada. E deve suportá-lo sob as mais risonhas alegações: porque o salário de determinada classe é insuficiente para custeio do seu próprio transporte; porque a condição de determinados enfermos não permite o desembolso; porque, enfim, tocou o coração do parlamentar a penúria que vive uma camada da sociedade, como se a estreiteza de recursos não fosse, aliás, situação de quase toda esta população.

Uma norma, ao pretender alcançar gratuidade no transporte, deve prever o que o ordenamento já dispõe em regra geral: indicar a fonte de custeio. Ausente esta indicação, deve o Poder Executivo, ao sancioná-la ou ter notícia de sua promulgação, determinar a imediata revisão tarifária.

Sem fonte de custeio a norma não poderá gozar de aplicabilidade imediata, sob pena de pretender, de forma marota, adentrar na seara do legislador constituinte originário. Se o intento realmente for uma ampliação constitucional o processo legislativo deve ser aquele reservado ao constituinte derivado, com rito que respeite os procedimentos constitucionalmente definidos.

Sem fonte de custeio e tampouco a necessária revisão tarifária,

\footnotetext{
${ }^{15} \mathrm{Em}$ alguns Estados da Federação a competência é concorrente, sendo legítimos para iniciar o processo legislativo tanto o Chefe do Poder Executivo (Governador) como qualquer membro do Poder Legislativo (Deputados). É o caso, por exemplo, do Estado do Paraná, conforme ditames da Constituição Estadual. O estudo pode, também, ser visto sob esta ótica sem comprometimento da totalidade do que aqui apresentado e consoante as ressalvas apostas.

${ }^{16}$ Sendo prerrogativa exclusiva do Chefe do Poder Executivo, como no âmbito federal, ou quando presente a competência concorrente, como em alguns Estados da Federação, sendo a norma de iniciativa do Chefe do Poder Executivo a promulgação apresenta-se como um paradoxo, já que não sancionada, por aquela autoridade, lei de sua própria iniciativa.
}

A \& C R. de Dir. Administrativo e Constitucional, Belo Horizonte, ano 5, n. 21, p. 89-98, jul./set. 2005 
não se reveste, a norma, de aplicabilidade. A omissão do chefe do Poder Executivo, quando não ordena a revisão, faz com o que o diploma da gratuidade passe do que epigrafamos "quase-inconstitucional" para a teiga das normas inconstitucionais. E a estas, não deve obediência qualquer dos administrados.

Seu destino há de ser a fulminação por via de ação que pretenda a declaração de inconstitucionalidade, com efeitos ex-tunc e erga omnes. Sua imposição espanca-se com o mandado de segurança, remédio capaz de afastar arbitrariedade do agente público e que resguarda, com amparo constitucional, os direitos dos particulares.

Sua edição, proposição e discussão deveriam passar, quer seja por iniciativa do Poder Legislativo, quer seja por iniciativa do Poder Executivo, por uma análise mais responsável dos órgãos encarregados do controle prévio de constitucionalidade, traduzido em efetiva atuação das Comissões de Constituição e Justiça ou mesmo do Chefe do Poder Executivo. Silentes estes, resta ao judiciário a repressão. Ainda que recaia ela, em última análise, sobre o próprio povo, encarregado de custear todo um processo que nasce apoiado em muletas do albardar popular.

São propostas que divergem do que extraído das normas dos direitos fundamentais: apresentam-se como afronta a dignidade do ser humano ao conferir-lhe status destoante dos demais usuários. A gratuidade constitucional, já posta, conferindo aos maiores de 65 anos gratuidade no transporte coletivo urbano, traduz-se em adoção de controles, operacionais, para as empresas operadoras, permitindo efetivo acompanhamento - interesse de toda sociedade - do número de pagantes e não pagantes. Adotam, alguns, embarque em portas diferenciadas. Outros, assentamento em locais especiais dentro do veículo. Todos, porém, rotulando o não pagante como tal, impondo-lhe exposição desta condição.

Antes de constituir-se em privilégio ou condição de respeito, representa exposição desnecessária daqueles que deveriam ter normas a garantir-lhes o uso do serviço, pagando por ele. A gratuidade, de qualquer espécie, representa incapacidade do beneficiário em ter seu próprio sustento, demonstrando falha da sociedade, ou do Estado por ela constituído, no atendimento das necessidades básicas de parte de seu grupo.

\section{Bibliografia}

A \& C R. de Dir. Administrativo e Constitucional, Belo Horizonte, ano 5, n. 21, p. 89-98, jul./set. 2005 
AFONSO DA SILVA, José. Aplicabilidade das Normas Constitucionais. 6. ed. São Paulo: Malheiros, 2002.

BASTOS, Celso Ribeiro. Curso de Direito Constitucional. 20. ed. São Paulo: Saraiva, 1999.

BRASIL. Constituição da República Federativa do Brasil de 1988. Casa Civil. Subchefia para assuntos jurídicos. Disponível em: <http://www.presidencia.gov.br>. Acesso em: 19 maio 2005 .

BRASIL. Lei $n^{\circ}$ 8.987, de 13 de fevereiro de 1995. Dispõe sobre o regime de concessão e permissão da prestação de serviços públicos previsto no art. 175 da Constituição Federal, e dá outras providências. Casa Civil. Subchefia para assuntos jurídicos. Disponível em: < http://www.presidencia. gov.br>. Acesso em: 19 maio 2005.

BRASIL. Lei $n^{\circ}$ 9.074, de 07 de julho de 1995. Estabelece normas para outorga e prorrogações das concessões e permissões de serviços públicos e dá outras providências. Casa Civil. Subchefia para assuntos jurídicos. Disponível em: < http://www.presidencia.gov.br>. Acesso em: 19 maio 2005.

CLÈVE, Clèverson Merlin. Atividades Legislativa do Poder Executivo. 2. ed. São Paulo: Revista dos Tribunais, 2000.

GASPARINI, Diogenes. Direito Administrativo. 8. ed. São Paulo: Saraiva, 2003.

JUSTEN FILHO, Marçal. Curso de Direito Administrativo. São Paulo: Saraiva, 2005.

MEDAUAR, Odete (Coord.). Concessão de Serviço Público. São Paulo: Revista dos Tribunais, 1995.

MEIRELLES, Hely Lopes. Direito Administrativo Brasileiro. 28. ed. São Paulo: Malheiros, 2003.

MENDES DE SOUZA, Horácio Augusto. Regulação Jurídica do Transporte Rodoviário de Passageiros. Rio de Janeiro: Lúmen Juris, 2003.

NOGUEIRA DA SILVA, Paulo Napoleão. Curso de Direito Constitucional. 2. ed. São Paulo: Revista dos Tribunais, 1999.

Informação bibliográfica deste texto, conforme a NBR 6023:2002 da Associação Brasileira de Normas Técnicas (ABNT):

MALUF, Sérgio Roberto. Gratuidade sem custeio ou revisão tarifária no serviço público de transporte rodoviário de passageiros: o vitupério à constituição. A $\mathcal{E}^{2} \mathrm{C}$ Revista de Direito Administrativo e Constitucional, Belo Horizonte, ano 5, n. 21, p. 89-98, jul./set. 2005. 